\title{
Neuroprotective effect of ketamine/ xylazine on two rat models of Parkinson's disease
}

\section{M.M. Ferro ${ }^{1}$ M.E.M. Angelucci², J.A. Anselmo-Franci ${ }^{3}$, N.S. Canteras ${ }^{4}$ and C. Da Cunha ${ }^{2}$}

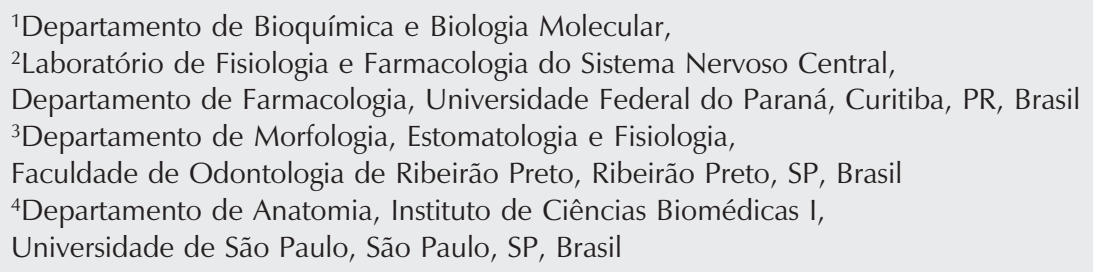

${ }^{1}$ Departamento de Bioquímica e Biologia Molecular, ${ }^{2}$ Laboratório de Fisiologia e Farmacologia do Sistema Nervoso Central, Departamento de Farmacologia, Universidade Federal do Paraná, Curitiba, PR, Brasil ${ }^{3}$ Departamento de Morfologia, Estomatologia e Fisiologia, Faculdade de Odontologia de Ribeirão Preto, Ribeirão Preto, SP, Brasil ${ }^{4}$ Departamento de Anatomia, Instituto de Ciências Biomédicas I, Universidade de São Paulo, São Paulo, SP, Brasil

\section{Correspondence \\ C. Da Cunha \\ Departamento de Farmacologia, UFPR \\ 81531-990 Curitiba, PR \\ Brasil \\ Fax: +55-41-3266-2042 \\ E-mail: dacunha@ufpr.br}

Research partly supported by CNPq, CAPES, and Fundação Araucaria.

Publication supported by FAPESP.

Received November 24, 2005 Accepted October 10, 2006

\begin{abstract}
There is a great concern in the literature for the development of neuroprotectant drugs to treat Parkinson's disease. Since anesthetic drugs have hyperpolarizing properties, they can possibly act as neuroprotectants. In the present study, we have investigated the neuroprotective effect of a mixture of ketamine $(85 \mathrm{mg} / \mathrm{kg})$ and xylazine $(3 \mathrm{mg} / \mathrm{kg})(\mathrm{K} / \mathrm{X})$ on the 1-methyl-4-phenyl-1,2,3,6tetrahydropyridine (MPTP) or 6-hydroxydopamine (6-OHDA) rat models of Parkinson's disease. The bilateral infusion of MPTP (100 $\mu \mathrm{g} / \mathrm{side})$ or 6-OHDA (10 $\mu \mathrm{g} / \mathrm{side})$ into the substantia nigra pars compacta of adult male Wistar rats under thiopental anesthesia caused a modest ( $\sim 67 \%)$ or severe $(\sim 91 \%)$ loss of tyrosine hydroxylase-immunostained cells, respectively. On the other hand, an apparent neuroprotective effect was observed when the rats were anesthetized with $\mathrm{K} / \mathrm{X}$, infused $5 \mathrm{~min}$ before surgery. This treatment caused loss of only $33 \%$ of the nigral tyrosine hydroxylase-immunostained cells due to the MPTP infusion and 51\% due to the 6-OHDA infusion. This neuroprotective effect of $\mathrm{K} / \mathrm{X}$ was also suggested by a less severe reduction of striatal dopamine levels in animals treated with these neurotoxins. In the working memory version of the Morris water maze task, both MPTP- and 6-OHDA-lesioned animals spent nearly $10 \mathrm{~s}$ longer to find the hidden platform in the groups where the neurotoxins were infused under thiopental anesthesia, compared to control animals. This amnestic effect was not observed in rats infused with the neurotoxins under $\mathrm{K} / \mathrm{X}$ anesthesia. These results suggest that drugs with a pharmacological profile similar to that of $\mathrm{K} / \mathrm{X}$ may be useful to delay the progression of Parkinson's disease.
\end{abstract}

\section{Introduction}

Parkinson's disease is among the neurodegenerative diseases for which there is no treatment proved to be clinically effective to
Key words

- Neuroprotection

- 6-Hydroxydopamine

- 1-Methyl-4-phenyl-1,2,3,6tetrahydropyridine

- Ketamine

- Parkinson's disease ................ 
$(2,3)$. Indeed, mesencephalic dopaminergic cells are among the elements of the basal ganglia most vulnerable to neurodegeneration $(1,3)$. Therefore, it is of great interest to look for neuroprotective compounds for the treatment of Parkinson's disease.

6-Hydroxydopamine (6-OHDA) and 1methyl-4-phenyl-1,2,3,6-tetrahydropyridine (MPTP) cause large or partial loss of dopaminergic cells, respectively, in the $\mathrm{SNc}$ of rats. Their effects have been studied as models of the advanced or the early phase of Parkinson's disease (4-7). 6-OHDA induces nigral dopaminergic lesion mainly by generating reactive oxygen species as a result of its oxidation. This can occur spontaneously or be induced by monoamine oxidase or iron $(1,6)$. MPTP is converted into 1-methyl-4phenyl-peridinium $\left(\mathrm{MPP}^{+}\right)$by glial monoamine oxidase $\mathrm{B}$. $\mathrm{MPP}^{+}$accumulates in $\mathrm{SNc}$ dopaminergic cells and acts mainly by inhibiting mitochondrial complex I, leading to a decrease in cellular ATP levels and cell death (8).

Sodium thiopental and a mixture of ketamine/xylazine $(\mathrm{K} / \mathrm{X})$ have been used to anesthetize rats during surgery for intracerebral administration of MPTP or 6-OHDA. In the present study, we report that lesions of the $\mathrm{SNc}$ (induced by MPTP or 6-OHDA) were amnestic only when the rats were operated under thiopental, but not under K/X anesthesia. The aim of the present investigation was to study whether the NMDA receptor antagonist, ketamine, has a neuroprotective effect on the MPTP and 6-OHDA rat models of Parkinson's disease.

\section{Material and Methods}

\section{Animals}

Adult male Wistar rats from our own breeding colony weighing $270-320 \mathrm{~g}$ at the beginning of the experiments were used. The animals were maintained in a temperature-controlled room $\left(22 \pm 2^{\circ} \mathrm{C}\right)$ on a $12 / 12$ - h light cycle (lights on at 7:00 am) and had free access to food and water. All efforts were made to minimize animal suffering and the recommendations of the Brazilian Laws and the National Institutes of Health guide for experimental animal care (9) were strictly followed.

\section{Surgery and drug treatments}

The animals were divided into the following groups: 1) control, $\mathrm{N}=10$; 2) thiopental MPTP, $\mathrm{N}=15 ; 3$ ) thiopental 6-OHDA, $\mathrm{N}=15$; 4) K/X MPTP, $\mathrm{N}=15$, and 5) K/X 6OHDA, $\mathrm{N}=15$. Group 2 and 3 animals were anesthetized with $40 \mathrm{mg} / \mathrm{kg}$ sodium thiopental, ip, while group 4 and 5 animals were anesthetized with $85 \mathrm{mg} / \mathrm{kg}$ ketamine, ip, and $3 \mathrm{mg} / \mathrm{kg}$ xylazine, ip. MPTP-HCl (100 $\mu \mathrm{g}$ in $1 \mu \mathrm{L}$ saline; Sigma, St. Louis, MO, USA) or 6-OHDA (Sigma; $6 \mu \mathrm{g}$ in $2 \mu \mathrm{L}$ artificial cerebrospinal fluid consisting of $8.66 \mathrm{~g} \mathrm{NaCl}, 0.205 \mathrm{mg} \mathrm{KCl}, 0.176 \mathrm{~g} \mathrm{CaCl}_{2}$. $2 \mathrm{H}_{2} \mathrm{O}$, and $0.173 \mathrm{~g} \mathrm{MgCl}_{2} \cdot 6 \mathrm{H}_{2} \mathrm{O}$ in 1 liter of water, plus $0.2 \%$ ascorbic acid) was infused into the SNc through a 30-gauge stainless steel needle at a rate of $0.33 \mu \mathrm{L} / \mathrm{min}$, at the following coordinates: anteroposterior -5.0 $\mathrm{mm}$ from the bregma, mediolateral $\pm 2.1 \mathrm{~mm}$ from the midline, and dorsoventral $-7.7 \mathrm{~mm}$ from the skull. During the first 5 postoperative days the animals were fed a pasty diet consisting of a mixture of crumbled ration and water. After that time, the animals were no longer aphagic or adipsic, and presented no gross motor deficit that could affect their performance during the memory tasks. Two additional groups were submitted to surgery in which artificial cerebrospinal fluid was infused under thiopental or K/X anesthesia. These treatments did not significantly affect cell death, as shown in the Results section by the striatal levels of dopamine and 3,4-dihydroxyphenylacetic acid (DOPAC) when compared to the non-operated group (Figure 3 ). These data were pooled and referred to as the control group in the Results section. 


\section{Water maze test}

Three weeks after surgery, the animals were submitted to a working memory version of the Morris water maze task (6). The animals were submitted to 4 consecutive trials per day over 5 training days. The escape platform remained in the same place during the trials conducted on the same day, but was moved to another quadrant of the tank, day by day, thus forcing the animals to use their working memory to find it. The tank was videotaped and the scores for latency to reach the escape platform and the swimming speed were later computed with an image analyzer (CEFET, Curitiba, PR, Brazil). Escape latencies for all training days in the water maze were averaged by trial.

Tyrosine hydroxylase immunohistochemistry and tyrosine hydroxylase-immunoreactive cell count

Fifty-five days after surgery, the animals were sacrificed and the midbrains were placed in $4 \%$ formalin for 1 week and then in $20 \%$ sucrose formalin for $48 \mathrm{~h}$ before sectioning. The brainstems were frozen and series of $30-\mu \mathrm{m}$ thick sections were cut with a sliding microtome on the frontal plane. One series of sections was immunostained for tyrosine hydroxylase (TH) with a monoclonal anti-TH antibody raised in mice (Incstar Corp., Stillwater, MN, USA) at a 1:5000 dilution. The primary antiserum was located by applying a variation of the avidinbiotin complex system using a commercially available kit (ABC Elite kit, Vector Laboratories, Burlingame, CA, USA) as described in a previous study (6). The number of THimmunoreactive neurons was determined using a 10X objective of a Nikon Eclipse E600 microscope equipped with a camera lucida by counting these neurons on both sides of the SNc and ventral tegmental area in 8 series of coronal sections located 360 $\mu \mathrm{m}$ apart, and the estimated counts were extrapolated using the method of Abercrombie (10). The borders defining the SNc and ventral tegmental area were determined from adjacent Nissl-stained sections that served as a reference for cytoarchitectural purposes.

\section{Determination of striatal monoamine levels}

The striata of the two hemispheres were dissected from the anterior part of the same brains. The endogenous levels of dopamine and DOPAC were assayed by reverse-phase high-performance liquid chromatography with electrochemical detection as described elsewhere (6). The reverse-phase high-performance liquid chromatography with electrochemical detection system consisted of a C18 reverse-phase column (Shim-pack, CLC-ODS, 250 x 4.6 mm; Shimadzu, Columbia, MD, USA), an amperometric electrochemical detector (Decade, VT-03 flow cell; Antec Leyden, Zoeterwoude, The Netherlands), and a liquid chromatography workstation (CLASS-VP 5032, Shimadzu). The oxidation potential was $+0.85 \mathrm{~V}$ versus an in situ $\mathrm{Ag} / \mathrm{AgCl}$ reference electrode (Antec Leyden). The peak areas of external standards were used to quantitate the peaks.

\section{Statistical analysis}

Differences between groups were analyzed by one-way (cell counts and monoamine levels) or two-way (memory scores) analysis of variance (ANOVA) with repeated measures (trials), followed by the NewmanKeuls test, with the level of significance set at $\mathrm{P}<0.05$.

\section{Results}

\section{Tyrosine hydroxylase count}

The results shown in Figures 1 and 2 are suggestive of a neuroprotective effect of K/ $\mathrm{X}$. Perinigral infusion of MPTP or 6-OHDA caused a significant reduction in the number 
Figure 1. Bright-field photomicrographs illustrating representative tyrosine hydroxylase-immunostained cell sections from the following experimental groups: $A$ animals anesthetized with thiopental receiving 1-methyl-4-phenyl-1,2,3,6-tetrahydropyridine ( $T$ MPTP) or B, 6-hydroxydopamine (T 6-OHDA), and $C$, animals anesthetized with ketamine and xylazine $(\mathrm{K} / \mathrm{X})$ receiving MPTP (K/X MPTP), or $D$, 6-OHDA (K/X 6-OHDA), and $E$, a control animal. Note that a smaller number of tyrosine hydroxylase-immunostained neurons was lost in the $\mathrm{SNc}$ of the animals anesthetized with $\mathrm{K} / \mathrm{X}(\mathrm{C}, \mathrm{D})$ compared to those anesthetized with thiopental (A, B). VTA = ventral tegmental area; $\mathrm{SNc}=$ substantia nigra pars compacta; $\mathrm{SNr}=$ substantia nigra pars reticulata. Scale bars $=200 \mu \mathrm{m}$. of the TH-immunoreactive neuron cells mainly in the $\mathrm{SNc}(\mathrm{F}(4,25)=22.93, \mathrm{P}<$ 0.001 , one-way ANOVA), spreading more modestly to the ventral tegmental area $(\mathrm{F}(4,25)=5.57, \mathrm{P}<0.001$, one-way ANOVA). 6-OHDA caused a significantly greater cell loss in the $\mathrm{SNc}$ compared to MPTP $(\mathrm{P}<0.05$, Newman-Keuls test $)$ when the animals were anesthetized with thiopental. A smaller loss of TH-immunostained neurons in the $\mathrm{SNc}$ was observed when the animals were anesthetized with $\mathrm{K} / \mathrm{X}$ prior to the infusion of 6-OHDA ( $\mathrm{P}<0.01$, Newman-Keuls test) or MPTP $(\mathrm{P}<0.05$, New-

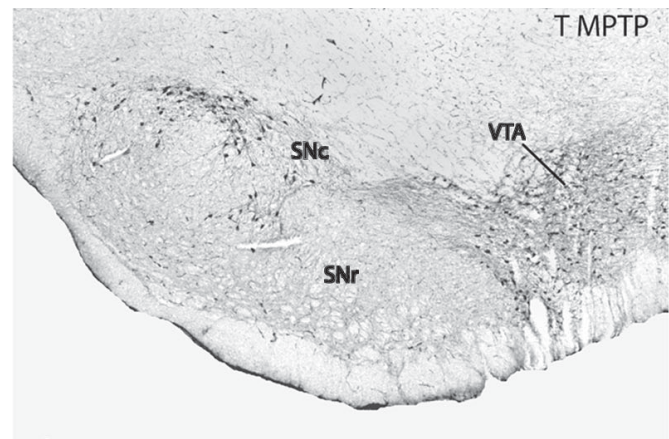

A

$-B$

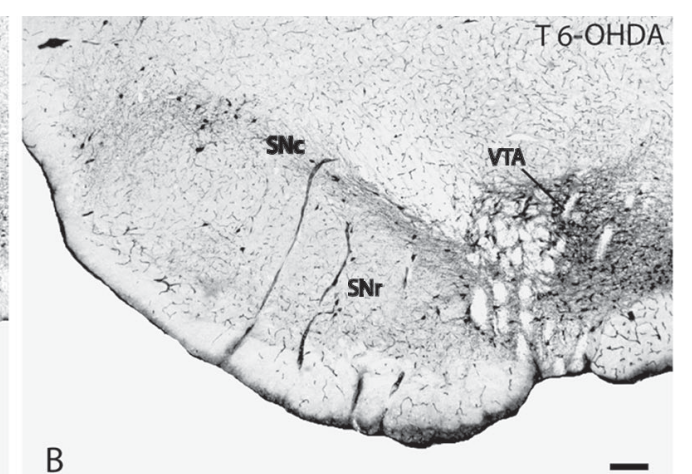

23
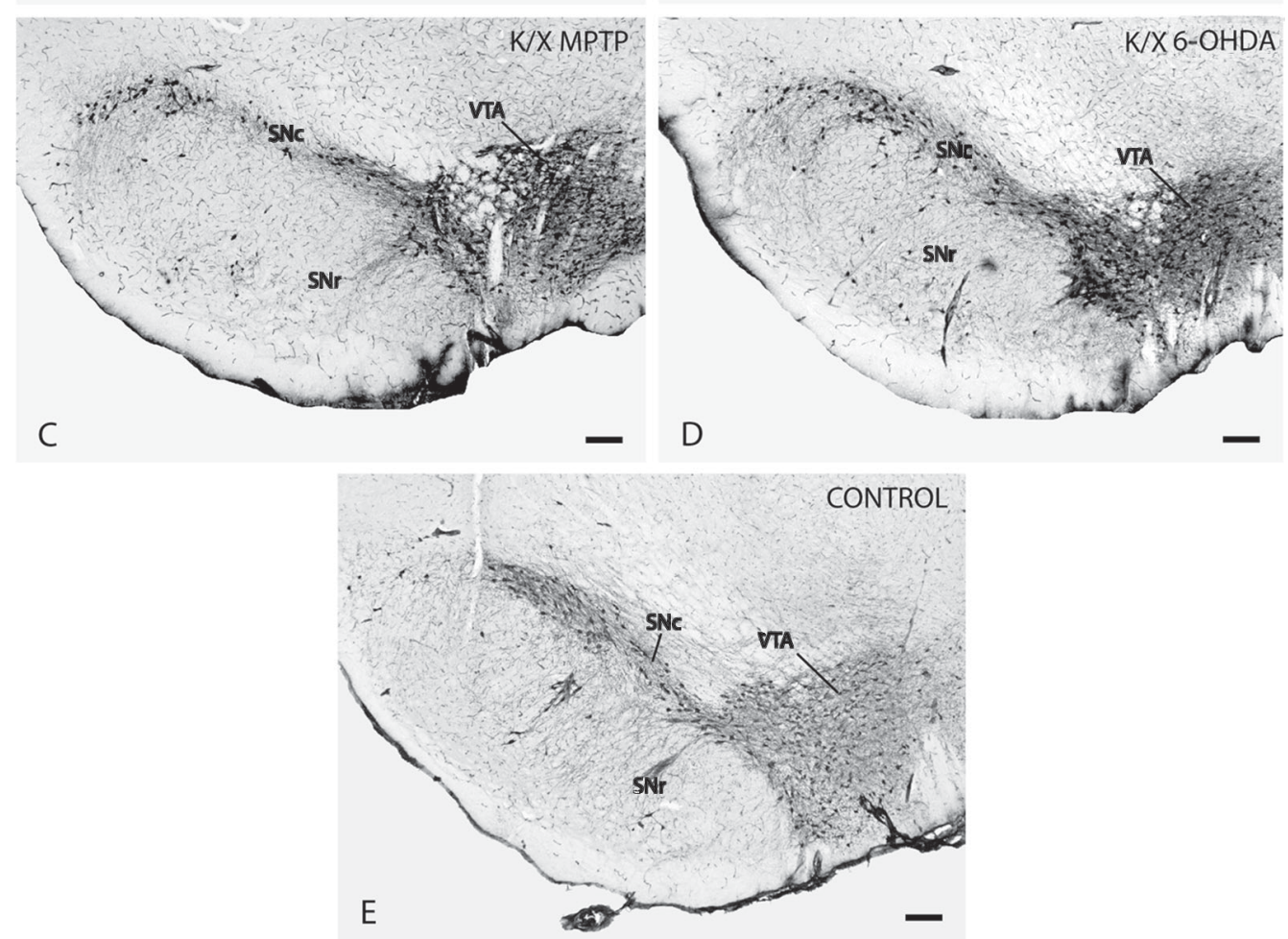

man-Keuls test) compared to animals anesthetized with thiopental.

\section{Dopamine depletion}

Analysis of striatal dopamine loss also suggests a neuroprotective effect of K/X. As shown in Figure 3, MPTP and 6-OHDA treatments also caused a significant reduction in the striatal levels of dopamine $(\mathrm{F}(4,48)$ $=83.15, \mathrm{P}<0.001$, one-way ANOVA; $\mathrm{P}<$ 0.001 , Newman-Keuls test) and DOPAC $(\mathrm{F}(4,48)=12.48, \mathrm{P}<0.001$, one-way ANOVA; $\mathrm{P}<0.001$, Newman-Keuls test). 
6-OHDA was more effective than MPTP in reducing dopamine levels in animals anesthetized with thiopental $(\mathrm{P}<0.05$, NewmanKeuls test), but no significant difference was observed between these groups when the animals were anesthetized with $\mathrm{K} / \mathrm{X}(\mathrm{P}=$ 0.21 , Newman-Keuls test). A significantly higher depletion of striatal dopamine was observed in the 6-OHDA thiopental group compared to the 6-OHDA K/X group $(\mathrm{P}<$
0.05, Newman-Keuls test). However, the level of DOPAC in the 6-OHDA K/X group did not differ significantly from that of the 6OHDA thiopental group ( $\mathrm{P}=0.09$, Newman-Keuls test). A neuroprotective effect of $\mathrm{K} / \mathrm{X}$ was observed for MPTP-lesioned rats in relation to DOPAC $(\mathrm{P}<0.05$, NewmanKeuls test), but not in relation to dopamine $(\mathrm{P}=0.33$, Newman-Keuls test $)$.
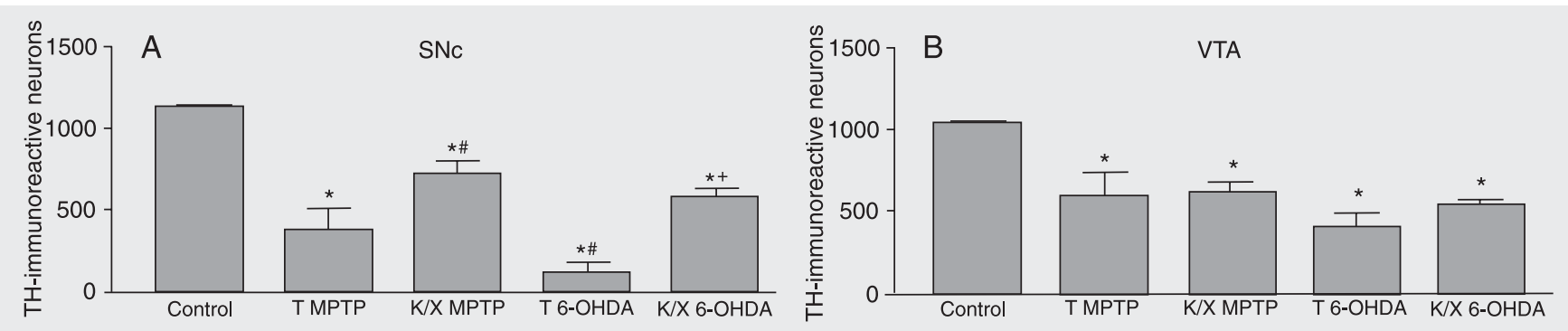

Figure 2. Unilateral counts of the number of tyrosine hydroxylase (TH)-immunoreactive neurons in complete series of sections through the substantia nigra pars compacta (SNc; A) and ventral tegmental area (VTA; B). Graphs show the corrected mean \pm SEM for each experimental group with 6 animals (Ref. 9). ${ }^{*} \mathrm{P} \leq 0.05$ compared to the control group; ${ }^{*} \mathrm{P} \leq 0.05$ compared to the thiopental 1-methyl-4-phenyl-1,2,3,6-tetrahydropyridine (T MPTP) group; ${ }^{+} \mathrm{P} \leq 0.05$ compared to the thiopental 6-hydroxydopamine (T 6-OHDA) group (ANOVA followed by the Newman-Keuls test). K/X $=$ ketamine/ xylazine anesthesia.
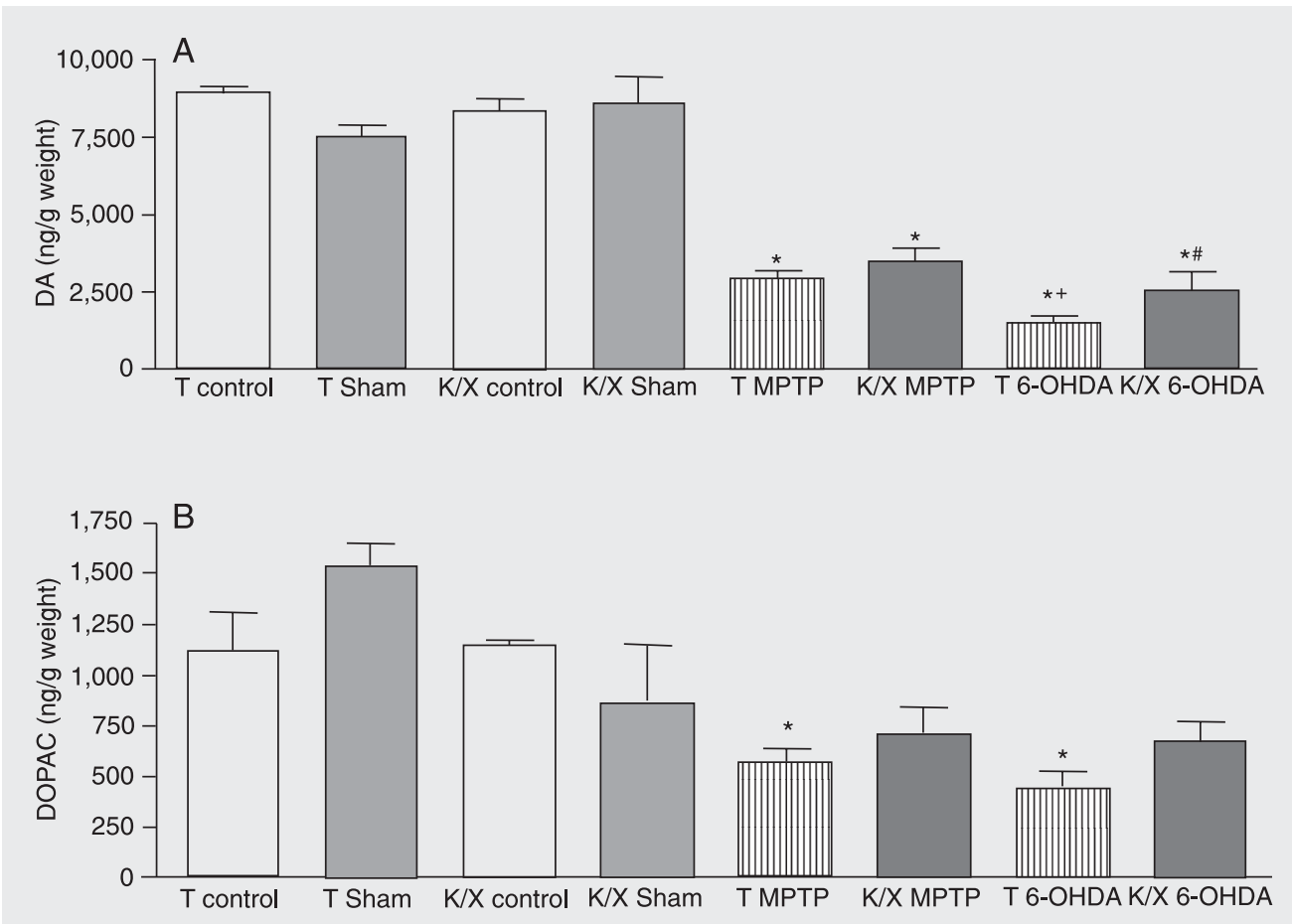

Figure 3. Striatal dopamine (DA) (A) and 3,4-dihydroxyphenylacetic acid (DOPAC) (B) concentrations after 1-methyl-4-phenyl1,2,3,6-tetrahydropyridine (MPTP) or 6-hydroxydopamine (6-OHDA) administration into the rat substantia nigra pars compacta under thiopental (T) or ketamine/ xylazine $(K / X)$ anesthesia. Two sham-operated groups are shown for comparison with the control groups. T MPTP: $\mathrm{N}=9$; T 6-OHDA: $\mathrm{N}=9$; K/X MPTP: $\mathrm{N}$ $=7 ; \mathrm{K} / \mathrm{X}$ 6-OHDA: $\mathrm{N}=7$; sham groups: $\mathrm{N}=6$, and control groups: $N=6$. Bars represent the mean \pm SEM. ${ }^{*} P \leq 0.05$ compared to the control group; ${ }^{\# P} \leq$ 0.05 compared to the T 6-OHDA group; ${ }^{+} \mathrm{P} \leq 0.05$ compared to the $\mathrm{K} / \mathrm{X}$ 6-OHDA group (oneway ANOVA followed by the Newman-Keuls test). 


\section{Water maze test}

The differences of working memory between thiopental and $\mathrm{K} / \mathrm{X}$ anesthetized animals also suggest a neuroprotective effect of the latter anesthetic. The data in Figure 4A and $\mathrm{B}$ are shown in different graphics, in order to facilitate comparison of the neuroprotective effects of the anesthetics, but the data of all groups were analyzed together. As can be seen, MPTP- and 6-OHDA-lesioned animals presented worse scores in the water maze task compared to control animals only after being operated under thiopental anesthesia $(\mathrm{F}(4,71)=5.13, \mathrm{P} \leq 0.001$, two-way ANOVA, treatment factor; $\mathrm{P} \leq 0.05$ Newman-Keuls test). The MPTP- and 6OHDA-lesioned animals operated under thiopental anesthesia also traveled longer distances to find the hidden platform in the water maze (data not shown; $\mathrm{F}(4,71)=5.13$, $\mathrm{P} \leq 0.001$, two-way ANOVA, treatment factor; $\mathrm{P} \leq 0.05$, Newman-Keuls test). The average swimming speed of all groups tested was equivalent $(\mathrm{F}(4,71)=0.07, \mathrm{P}>0.2$, ANOVA).

\section{Discussion}

The present results suggest that anesthe-

Figure 4. Effect of ketamine/ xylazine $(\mathrm{K} / \mathrm{X})$ anesthesia with administration of 1-methyl-4phenyl-1,2,3,6-tetrahydropyridine (MPTP) or 6-hydroxydopamine (6-OHDA) into the rat substantia nigra pars compacta on the working memory version of the Morris water maze task. Data of 5 training days were averaged for each of 4 consecutive trials and reported as mean \pm SEM latency to find the platform. Thiopental MPTP: $N=14$; thiopental 6-OHDA: $\mathrm{N}=10 ; \mathrm{K} / \mathrm{X}$ MPTP: $\mathrm{N}=$ 13; K/X 6-OHDA: $N=9$, and control groups: $\mathrm{N}=14$. ${ }^{*} \mathrm{P} \leq 0.05$ compared to control group; $+\mathrm{P} \leq$ 0.05 compared to $\mathrm{K} / \mathrm{X}$ group (two-way ANOVA, followed by the Newman-Keuls test).

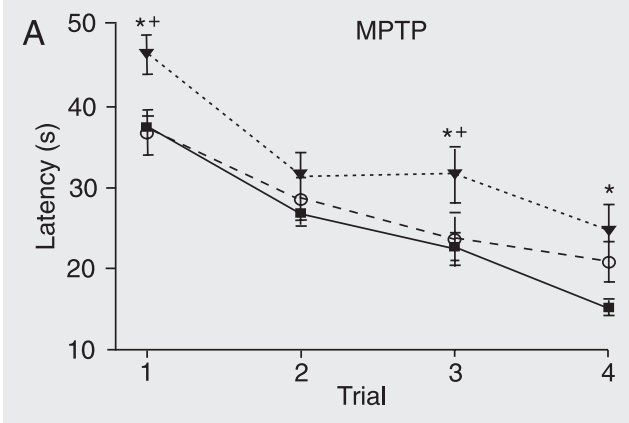

of the animals in a test sensitive to changes in the nigrostriatal pathway. One exception was observed regarding striatal dopamine depletion when the lesion was induced with MPTP. Since MPTP caused a more modest depletion of dopamine compared to 6OHDA, it is possible that the neuroprotective effect of $\mathrm{K} / \mathrm{X}$ was more evident in the latter case.

The blockade of NMDA receptors by ketamine is a possible mechanism whereby the $\mathrm{K} / \mathrm{X}$ mixture protected $\mathrm{SNc}$ neurons against the MPTP insult since neuroprotection of SNc cells against the MPTP or MPP ${ }^{+}$ insult by NMDA receptor antagonists has been reported (11-14). However, the noncompetitive NMDA receptor antagonist, MK-801, failed to protect rats against $\mathrm{MPP}^{+}$ and mice against MPTP neurotoxicity (1517). The observed neuroprotective effect of ketamine may also be mediated by its dopamine $D_{2}$ receptor agonist action, as is the case for other agonists such as pramipexole reported to be neuroprotective against MPTP and 6-OHDA lesions (18).

Alternatively, ketamine has been reported to act as an inhibitor of 6-OHDA uptake and as a scavenger of free radicals in dopaminergic neurons. Datla and co-workers (19) have shown that higher doses of 6-OHDA $(10 \mu \mathrm{g})$ were necessary to provoke significant depletion of SNc TH-immunostained cells and dopaminergic depletion in the rat.

The neuroprotective effect of $\mathrm{K} / \mathrm{X}$ was sufficient to prevent working memory impairment caused by both MPTP and 6-OHDA

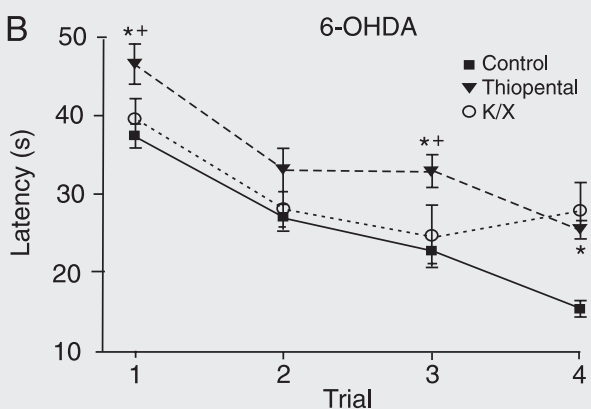


lesions. This result probably was not due to a motor impairment since, at the time of this test, the animals swam normally and the latency to find the platform in the first trial of the first training day $(\mathrm{F}(4,71)=0.10, \mathrm{P}>0.2$, ANOVA) and the mean swimming speed $(\mathrm{F}(4,71)=0.07, \mathrm{P}>0.2$, ANOVA $)$ did not differ significantly between groups (20).

The percentages of loss of TH-immunostained cells and striatal dopamine in the same animals were not similar. It is possible that the surviving $\mathrm{SNc}$ cells increased the synthesis and/or release of dopamine in the striatum. During the early stages of the disease, the remaining cells maintain nigrostriatal function at normal physiological levels.

For this reason, Parkinson's disease patients start to develop motor symptoms only when almost $75 \%$ of their dopaminergic ni- grostriatal neurons have died.

Cognitive deficits have been reported in rat models $(4,6,7,20,21)$ and in the early stages of Parkinson's disease, even before the onset of motor symptoms (22). Since MPTP- and 6-OHDA-lesioned rats model the early and advanced phases of Parkinson's disease, respectively, the present results encourage future studies to test whether the observed neuroprotective effect of $\mathrm{K} / \mathrm{X}$ would delay neurodegeneration in both phases of this disease.

\section{Acknowledgments}

The skillful assistance of Ivana Kouzmine, Samantha Wietzikoski, and Ana Maria Peraçoli Campos is acknowledged.

\section{References}

1. Dawson TM, Dawson VL. Molecular pathways of neurodegeneration in Parkinson's disease. Science 2003; 302: 819-822.

2. Damier P, Hirsch EC, Agid Y, Graybiel AM. The substantia nigra of the human brain. II. Patterns of loss of dopamine-containing neurons in Parkinson's disease. Brain 1999; 122 (Pt 8): 1437-1448.

3. Fearnley JM, Lees AJ. Ageing and Parkinson's disease: substantia nigra regional selectivity. Brain 1991; 114: 2283-2301.

4. Da Cunha C, Angelucci ME, Canteras NS, Wonnacott S, Takahashi $\mathrm{RN}$. The lesion of the rat substantia nigra pars compacta dopaminergic neurons as a model for Parkinson's disease memory disabilities. Cell Mol Neurobiol 2002; 22: 227-237.

5. Schwarting RK, Huston JP. The unilateral 6-hydroxydopamine lesion model in behavioral brain research. Analysis of functional deficits, recovery and treatments. Prog Neurobiol 1996; 50: 275-331.

6. Da Cunha C, Wietzikoski S, Wietzikoski EC, Miyoshi E, Ferro MM, Anselmo-Franci JA, et al. Evidence for the substantia nigra pars compacta as an essential component of a memory system independent of the hippocampal memory system. Neurobiol Learn Mem 2003; 79: 236-242.

7. Ferro MM, Bellissimo MI, Anselmo-Franci JA, Angellucci ME, Canteras NS, Da Cunha C. Comparison of bilaterally 6-OHDA- and MPTP-lesioned rats as models of the early phase of Parkinson's disease: histological, neurochemical, motor and memory alterations. J Neurosci Methods 2005; 148: 78-87.

8. Blum D, Torch S, Lambeng N, Nissou M, Benabid AL, Sadoul R, et al. Molecular pathways involved in the neurotoxicity of 6-OHDA, dopamine and MPTP: contribution to the apoptotic theory in Parkinson's disease. Prog Neurobiol 2001; 65: 135-172.

9. National Institutes of Health. Guide for the care and use of laboratory animals. http://www.nap.edu/readingroom/books/labrats. Ac- cessed August 28, 2006.

10. Abercrombie M. Estimation of nuclear population of microtome sections. Anat Rec 1946; 94: 239-247.

11. Tabatabaei A, Perry TL, Hansen S, Krieger C. Partial protective effect of MK-801 on MPTP-induced reduction of striatal dopamine in mice. Neurosci Lett 1992; 141: 192-194.

12. Lange KW, Loschmann PA, Sofic E, Burg M, Horowski R, Kalveram $\mathrm{KT}$, et al. The competitive NMDA antagonist CPP protects substantia nigra neurons from MPTP-induced degeneration in primates. Naunyn Schmiedebergs Arch Pharmacol 1993; 348: 586-592.

13. Zuddas A, Oberto G, Vaglini F, Fascetti F, Fornai F, Corsini GU. MK801 prevents 1-methyl-4-phenyl-1,2,3,6-tetrahydropyridine-induced parkinsonism in primates. $J$ Neurochem 1992; 59: 733-739.

14. Ossowska K. The role of excitatory amino acids in experimental models of Parkinson's disease. J Neural Transm Park Dis Dement Sect 1994; 8: 39-71.

15. Sonsalla PK, Zeevalk GD, Manzino L, Giovanni A, Nicklas WJ. MK801 fails to protect against the dopaminergic neuropathology produced by systemic 1-methyl-4-phenyl-1,2,3,6-tetrahydropyridine in mice or intranigral 1-methyl-4-phenylpyridinium in rats. J Neurochem 1992; 58: 1979-1982.

16. Finiels-Marlier F, Marini AM, Williams P, Paul SM. The N-methyl-Daspartate antagonist MK-801 fails to protect dopaminergic neurons from 1-methyl-4-phenylpyridinium toxicity in vitro. $J$ Neurochem 1993; 60: 1968-1971.

17. Michel PP, Agid Y. The glutamate antagonist, MK-801, does not prevent dopaminergic cell death induced by the 1-methyl-4phenylpyridinium ion (MPP+) in rat dissociated mesencephalic cultures. Brain Res 1992; 597: 233-240.

18. Schapira AH. Neuroprotection and dopamine agonists. Neurology 
2002; 58: S9-S18.

19. Datla KP, Zbarsky V, Dexter DT. Effects of anaesthetics on the loss of nigrostriatal dopaminergic neurons by 6-hydroxydopamine in rats. J Neural Transm 2006; 113: 583-591.

20. Hefco V, Yamada K, Hefco A, Hritcu L, Tiron A, Nabeshima T. Role of the mesotelencephalic dopamine system in learning and memory processes in the rat. Eur J Pharmacol 2003; 475: 55-60.

21. Miyoshi E, Wietzikoski S, Camplessei M, Silveira R, Takahashi RN,
Da Cunha C. Impaired learning in a spatial working memory version and in a cued version of the water maze in rats with MPTP-induced mesencephalic dopaminergic lesions. Brain Res Bull 2002; 58: 4147.

22. Reichmann H, Summer U, Gerlach M, Riederer P. Pharmacotherapy of idiopathic Parkinson's syndrome with special focus on neuroprotection. Dtsch Z Nervenheilkd 2001; 20: 227-310. 